\title{
Non-verbal Communication between Two Non- native English Speakers: Iraqi and Chinese
}

\author{
Khalid Wahaab Jabber \\ English Department, College of Basic Education, University of Misan, Maysan, Iraq \\ Aymen Adil Mahmood \\ Diyala Directorate of Education, Diyala, Iraq
}

\begin{abstract}
This study investigates non-verbal communications used by an Iraqi speaker to transfer meaning to a Chinese speaker and vice versa. Different situations, from Chinese environment, have been chosen and analyzed according to the body language movements. The study found out that although the two languages, Iraqi Arabic and Chinese, are differentiated in verbal languages; the two speakers can communicate and understand each other nonverbally. It is also evidence that non-verbal communication between the Iraqi and Chinese speakers is somewhat similar in spite of their two differentiated cultures, they could understand each other's facial expression, gestures, proxemics, haptics, and Tactile.
\end{abstract}

Index Terms —non-verbal communication, body language, non-native English, culture

\section{INTRODUCTION}

Language is a system of communication. It is an important part of human's real life situations, without language nothing is understood. We learn how to mean things through language and how to share all of those meanings with others (Halliday, 1993, p. 93). Edward Sapir, in his book published in 1921, related language to communication between human beings. For Sapir, language is non-instinctive and voluntary produced (Poole, 2000, p. 3). Robins (1980, p. 9-14 cited in Runqing, 2002, p. 2) considered the current language as trivial and uninformative unless they refer to some linguistics analysis and general theory of language. Another definition, which is quite deferent, is given by Chomsky (1957, p. 13 cited in Runqing, 2002, p. 2-3). Chomsky considers a language to be a " set (finite or infinite) of sentences, each finite in length and constructed out of a finite set of elements". For Chomsky, language is given by the society to the individual in which he/she lives. It is a part from serving the essential function of communication, e.g. giving and asking for information, language is a cultural and social tool for shaping human thought and reflecting human culture.

Sentences are scarcely produced in a behavioral vacuum. Our speech is colored and flavoured with a variety of natural vocal, gestures, and facial expression which indicate our internal aims to convey meaning that express our emotions and feelings (Wharton, 2009).

Communication is a way to transfer the meaning from one person to another for the same language or for different languages. According to Ben-Nun (2014, p. 93) communication is exchanging information or the use of common system of symbols, behavior for this, signs, a verbal or written message. a system of routes, techniques for the effective exchanging of information, idea, etc.

Communication can be achieved without words. In this respect, this kind is called non-verbal communication. It is a way to communicate using multiple forms of communication except words (Greene et al, 1994 cited in Caris-Verhallen et al, 1999, p. 809).

Culture is an essential part of the non-verbal communication. It means may be that there are several meaning come from one form of non-verbal communication according to the culture determined. For example, eyes gazing, in one culture can be regarded a positive case; while in another culture cause embarrassment being impolite. The problem of multiply of meaning of the same form belong to the people of different cultures (Topan, 2011, p. 132-133).

Studies conducted by Professor Paul Ekman in the late of 1950 showed that there are certain facial expressions (corresponding to certain emotions) that are the same for all the people, regardless of cultural background. Paul Ekman began his studies believing that gestures and body language in general were culturally conditioned, and therefore could be learned. His hypothesis later was proven to be invalid because the research he conducted in Papua New Guinea, Brazil, Japan, Argentina, the US or Indonesia proved that there are surprising similarities in how people express a set of basic emotions in all of these extremely different cultural regions (Topan, 2011, p. 135).

In the case of verbal communication is not effective because of language barriers, Non-verbal communication can substitute for verbal communication in a variety of ways. Language barriers are found when a person has not yet learned the language of a receiver or using incompatible codes which prevent both of interlocutors from understand each other ("Principles", 2014, p. 186). 
Iraqi Arabic and Chinese are non-native English speakers. In Chinese universities, English is the language of learning and teaching inside the university camp. When Iraqi students communicate with Chinese people out of the university camp, whether in market, hospital, parks, museums, etc., they face difficulties because of language barriers. Iraqi students try to use English language to communicate whereas most of chances in real life situation use Chinese language. Even of some of Chinese try to use simple English words to convey meaning, but the problem still exist because both of interlocutors do not understand each other. The best way that most of foreigners intend to use is nonverbal communication.

This study attempts to investigate the non-verbal communications which occurred in Chinese real life situations between an Iraqi speaker and a Chinese one. The researchers have chosen random situations in which they have faced during their period of study in China.

\section{NON-VERBAL COMMUNICATION}

Non-verbal communication is defined as not involving words of speech, voluntary or involuntary non-verbal signals, such as smiling or blushing (Ben-Nun 2014, p. 93). Non-verbal communication plays a major role in the general efficiency of the communication process. The verbal massage is better perceived when the non-verbal language further emphasizes it. When there is a conflict between what is said and the way it is said, people usually believe what they see and not what they hear (Topan, 2011, 134). Zoric et al (2007 cited in Barry et al, 2011, p.1) stated that non-verbal communication refers to all aspects of exchanging message without the use of words and it includes all expressive signs, cues and signals etc.

According to Ishikawa et al (2010 cited in Ben-Nun, 2014, p.10) non-verbal communication involves these nonverbal motive in a communication setting that are generated by both the source (speaker) and his or her use of the environment and have tolerable message value for the source or receiver (listener).

There are a wide range of non-verbal communication behaviors. They include; facial expression, eye gaze, postures, proxemics, physical attractiveness, hair and clothing style...etc. (Hess, 2016).

Studies have shown that about 55-97 \% of the messages communicated are non-verbal. Studies indicate that human communication, particularly face-to-face communication, is predominantly non-verbal (Gross, 1990 cited in CarisVerhallen et al, 1999, p. 809; Topan, 2011, p. 132; Gurrero \& Floyd, 2006; Yang, 2017, p. 128).

Research contacted by Mehrabian (1981 cited in Yang, 2017, p. 128) shows that more than 90\% of human communication is related to non-verbal behavior and less than $10 \%$ is relevant to words, this is because the amount of time when we do not talk is much longer than that when we do talk.

Non-verbal communication regarded as an essential part of human existence. It has a wide range of implications for our everyday (Ben-Nun, 2014, p. 93). Non-verbal communication includes physical communication; like salute, smell, posture and other bodily movements; facial expressions such as yawning, raising sneezing, eyebrows, rolling eyes, a smile, gaping, wink, nodding and frown; gestures: waving, pointing, and using fingers to indicate numeric amounts; paralinguistic such as vocal communication, separate from actual language, including tone of voice, loudness, inflection and pitch; proxemics: the need for "person space", eye gaze: looking, contact, staring and blinking; haptics: communication through touch; appearance: choice of color, clothing, hairstyle and other factors affecting appearance; aesthetic communication: creative expression; music, dance, theatre, painting, and sculpture; signs: signal flags or lights, a display of air plants information, sirens and horns; symbols: jewelry, clothing, and cars.

Dinica (2014, p. 17) categorized body language communication to facial expressions, body movements (gestures), form and posture, general appearance and tactile communication.

Gestures are an individual's way of communicating as most people gesture when they talk. Intentional movements and signals are an important way to exchange meaning without words. Common gestures include pointing, waving, and using fingers to indicate numeric amounts. Other gestures are arbitrary and related to culture. Gesturing is a robust phenomena found across, cultures, tasks and ages, in individuals blind gesture is found from the birth because they have no ability to communicate verbally. Gesture can play a role in communication and thought in many times extension. Gestures are reflection of speaker's thought, unspoken thought, and thus regarded as window onto cognition (Ben-Nun, 2014, p. 14).

Tactile communication is manifested by the frequency of touch, the way to shake hands, making arm, hug mode, struck on the shoulder, etc. Tactile communication depends on type of hello, age, culture and relationship (Tanase, 1993 cited in Dinica, 2014).

Appearance deals with person's look or physical aspects of body shape, like hairstyle, color, dress. Different colors can cause different moods. Appearance can change physiological reactions, interpretations and judgments (Ben-Nun, 2014, p. 18).

Dupont (1994) and Hall \& Hall (1990) mention that facial expression communication includes (frown, raise nose wrinkling, lips, eyebrows, climbing etc.), smile, eye (or avoiding eye contact, gaze direction, eye expression). According to Dupont and Hall \& Hall, smiling is a complex gesture able to express a wide range of information like pleasure, surprise, joy and wrinkled nose (cited in Dinica, 2014). 
Posture is another kind of body movements, posture is a social status that individual have, think to have or want to have. Posture can convey a wide range of information about the emotions, attitudes, degree of courtesy, warmth. For instance, a predominant person tends to keep his head titled up and down over the subject (Dinica, 2014, p. 108).

\section{ANALYSIS AND DISCUSSION}

This part deals with the analysis of the chosen situations, firstly the researchers try to describe the situation and secondly attempt to demonstrate the way interlocutors were communicated non-verbally. Each situation implies a conversation between the two interlocutors and followed by a figure illustrates the way of non-verbally communication.

\section{A. Taking a Taxi}

In our daily life, the significant thing is to move from one place to another to do something, achieve or obtain things. The following situation happened with a driver. One day, when a speaker was in China, he went to the hospital for a medical treatment. Unfortunately, the taxi driver and a speaker cannot understand each other verbally.

Speaker: to the hospital, please.

Chinese driver: began speaking some Chinese words.

Speaker: Oh, how to say?

Chinese driver: "smiling"

In above conversation we see that a Chinese driver used facial expression that is smiling to indicate that he still not understand what a speaker is talking about. From the other hand, as a reflection to the Chinese driver, a speaker began to use gestures to tell the driver the way to the hospital. His first step is by waving his right hand to the (right side) to show the taxi driver the way that what he wanted to go to. The taxi driver turned the car to the right side. Then, a speaker waved his hand to the left side as a sign that the driver should move to the left side. Also, he used a hand in straight way to let the driver keep going straight. A speaker repeated waving his hands more than one time to the right, to the left and straight forwards until the driver reached to the hospital. In fig 1-2 a speaker shows to a Chinese driver the way.

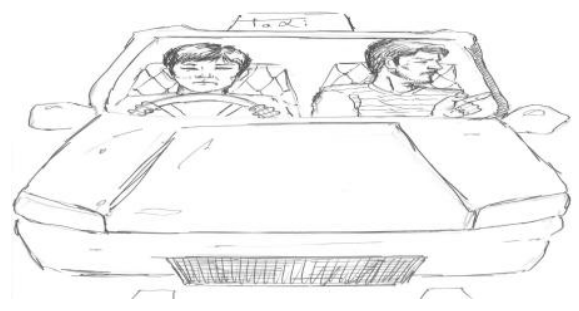

Figure 1 A speaker points to the lift side

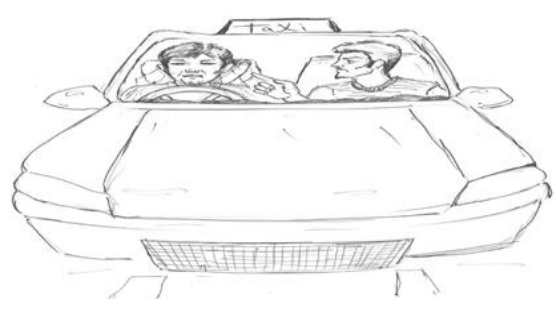

Figure 2 A speaker points to the right side

\section{B. At JI MAO Market (Buying Tools)}

Markets are found to make our daily life easier. When someone finds him/herself in a place that the seller cannot share the same language of communication, therefore, the only way to communicate is by using nonverbal communication. The following situations are in (JI MAO) market in China, Wuhan city, Huazhong University of Science and Technology to buy Barbecue (BBQ) tool. When an Iraqi tried to communicate with the seller orally, he faced difficulty to convey him his message.

Buyer: please, do you have Barbecue tool?

Seller: "raise nose wrinkling"

Buyer: tool for barbecue food!

Seller: immmmmm- "he seems puzzled"

Chinese seller began his replying by raising his nose wrinkling, this nonverbal movement expresses that he did not understand the order. When the speaker repeated the word of order, Chinese seller expressed his attitude by feelings of puzzling and put his hand under his nick. Therefore, in this moment, a speaker tries to act the barbecue process by imitating to the person or the man who trying to do something like BBQ. Firstly, a speaker tries to point by his hand at one of the nearby cartoons. Secondly, he hit his right fingers with left hand as a sign to setting fire. Finally, he turned the palm of his hands on the box up and down while still staring at the seller's eyes. Fig 3 shows how an Iraqi speaker describes to the Chinese seller a tool he wants to buy. 


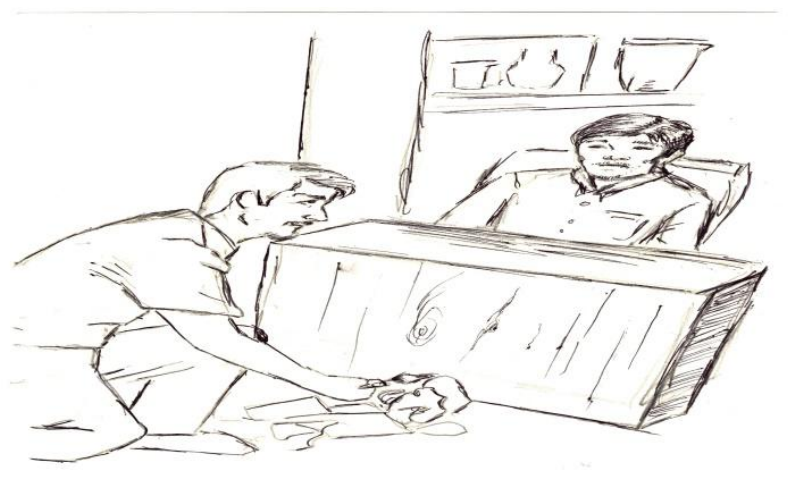

Figure 3 A speaker describes the purpose of barbecue

\section{At the Hospital}

The following situation is in (REN MEN) hospital in China, Wuhan city. When an Iraqi's daughter had urinary tract infection. One day, an Iraqi speaker woke up and he noticed that his daughter has a small of a drop of blood coming out with her urine. When he arrived to the (REN MEN) hospital he faced a big problem to explain the doctors what his daughter suffered.

Speaker: doctor, (in referring to her daughter), her urine is red!

Doctor: reddddd!

Speaker: Yes; red, red...

Doctor: "eyes gazing"

Doctor appears amazed to hear the word 'red' but his eyes gazing indicates that he still confused and needs more detail. An Iraqi speaker began his first signal by referring to a man who tries to go to the WC and using it in fact. Tried to get access to the WC with virtual steps back and then forth. Then, he brought red polish nails with dropping red color in glass of water through urine.A speaker through this operation looked onetime to a doctor and one another to his daughter in order to give hint to the doctor that this blood is from his daughter. In fig 4 a speaker describes to a doctor the health case of his daughter.

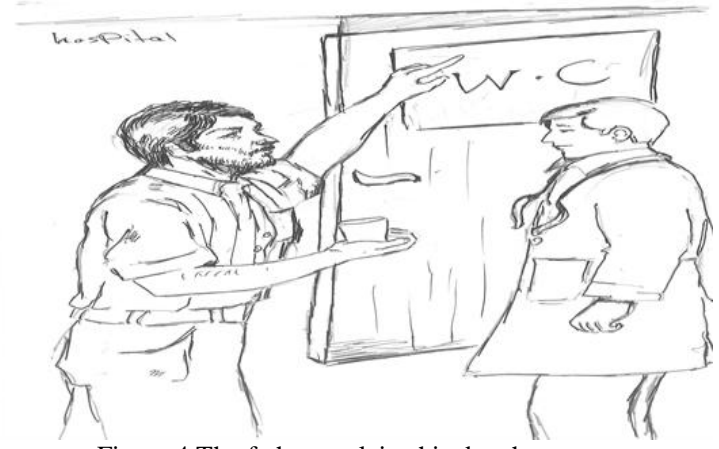

Figure 4 The father explains his daughter case

\section{At Printer Office}

To keep some important documents, we must put it in a safe place; in other words, we must copy it into several copies. Conversely, the human being intends the printing office in order to keep the significant documents, such as pictures, certificates, contracts and so on. The following situation happened in China, Wuhan city, HUST. When an Iraqi wanted to copy his documents for the first time.

Speaker: I want to copy this paper.

Employee: "refers to the bundles of papers"

Speaker: No- "waving his right hand"

"Pointing to the printer"

With regard to employee, he seems to be confused. He thought that the speaker wants to buy papers. Therefore, he pointed by his finger to the bundles of papers. A Chinese printer thought that the speaker wants to buy some papers. An Iraqi speaker replying to the Chinese printer was by pointing to the printer. He began illustrating to the printer what he wants to copy. He held by his right hand a white paper and put it beside the document which he wanted to copy. Then, he moved the blank paper over the document several times with pointing to printer to transfer the message to the employee that he needs two copies of them. After several attempts, the employee did what a speaker wanted to do. Fig 5 shows a speaker description of the number of papers he needs to copy. 


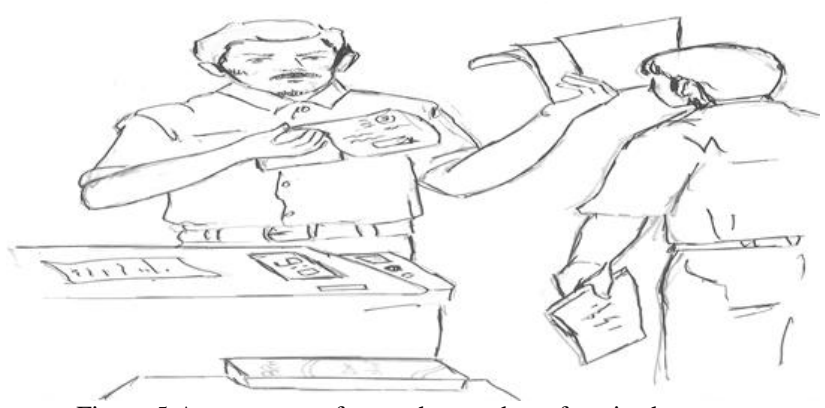

Figure 5 A customer refers to the number of copies he wants

\section{E. At Metro Station}

The transportation plays a significant role in the Chinese daily life. With the development of this means the human being creates things to make it easier, for instance metro card which is used to pay the transportation fees. The following situation happened in Wuhan metro station. One day an Iraqi wanted to go from Optic Valley Square Station to Xunlimen Station.

Speaker: recharge this card, 30 Yuan.

Chinese employee: "catches the card, rolling it right and left"

Speaker: No, ? re...charch?

Chinese employee: "no reply" (rolling his eyes)

Speaker: show the employee a Chinese currency.

For the first time, an employee believed that the Iraqi speaker wants to check his card, so he turned the card right and left. An Iraqi speaker's answer was by showing a Chinese employee the money as a sign that he wants to recharge the card. To tell the employee the amount of money, he wants to recharge, an Iraqi speaker held 20 Chinese Yuan in one hand and the card in another hand then trying to touch both of them together and then put the money and the card in one hand. The staff member has understood the message and recharge his metro card. Fig 6 shows the amount of money the speaker wanted to recharge metro card.

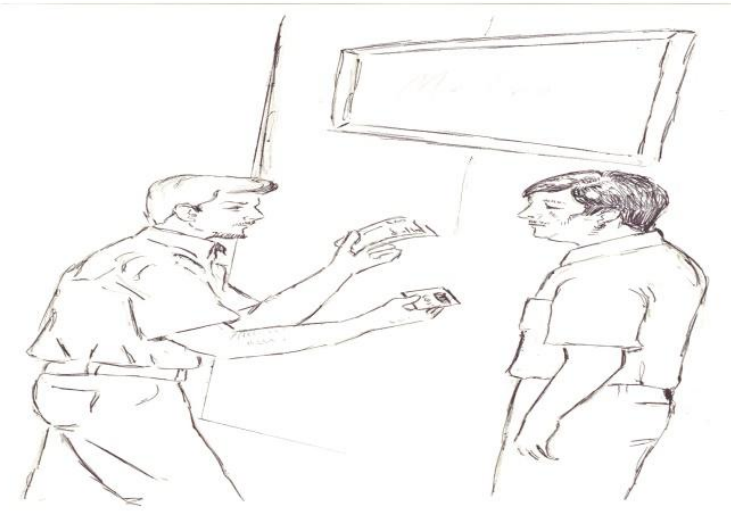

Figure 6 A speaker shows the amounts of money he wants to recharge

\section{F. At the Meat Market}

The following situation occurred in the meat shop in China, Wuhan city. When an Iraqi went with a country mate to buy meat

Buyer: 2 kills from this piece, please.

Butcher: "Bucher refers to a mass of meat"

Buyer: Cut for me a piece from here and divide it into small pieces.

Butcher: "stay gazing without saying any word"

Chinese butcher didn't know the amount of meat that the buyer wants, he merely referring to the piece of meat, and then stay gazing at the speaker face. Her eyes tell that he has confusing to realize the speaker's idea. An Iraqi speaker tried to illustrate the idea, to ask that he wants two kills of meat, he pointed his two fingers to the butcher face. After that, he passed his hand parallel to hanging piece of meat and moved it from the top to the bottom vertically. This movements tell that he wants a piece from this big piece of meat. After that, a speaker put palm of one hand flat upward and another hand vertically on the first hand like cross sign. He beat by the vertical hand on the flat hand several times from top to the bottom to tell the butcher that he wants to cut the piece of meat into small pieces. In fig 7 a speaker describes to the butcher the number of meat's pieces he wants. 


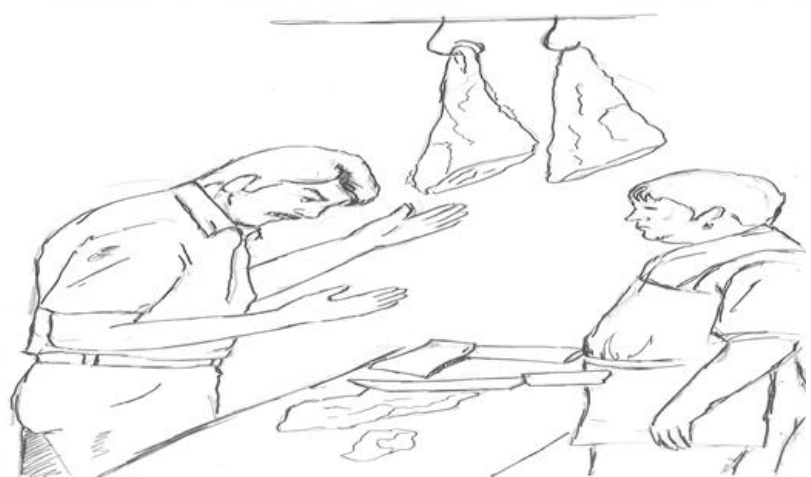

Figure 7 A buyer illustrates the kind of meat pieces he wants

\section{G. Buying Shampoo}

The cosmetics factories are making many types of shampoo not for hair only, but for the body also. Therefore, we must distinguish between both by reading the information on it. In China, there is a big trouble for foreigners to recognize the contents and structures of the materials of products because everything is written in Chinese language. The following situation is in (Carrefour Mall) in Wuhan city.

Buyer: which one is used for hear?

Seller: hearrrrr??

Buyer: yes, for hear.

Seller: "waving her hands up"

When an Iraqi speaker wanted to buy shampoo he doesn't know to choose one for hear, he called some staff, but she couldn't speak English. To be contact with an employee, he acted as one wish his head with shampoo like one person taking a shower and putting his hands on his head and moving them in complete circles from right to left and conversely. In that moment, the lady sent his message, by moving her hand on her body as a complete circle from side to another that this type of shampoo is not for hair but for body. Fig 8 shows how a speaker describes to a shop assistant the kind of shampoo he wants to buy.

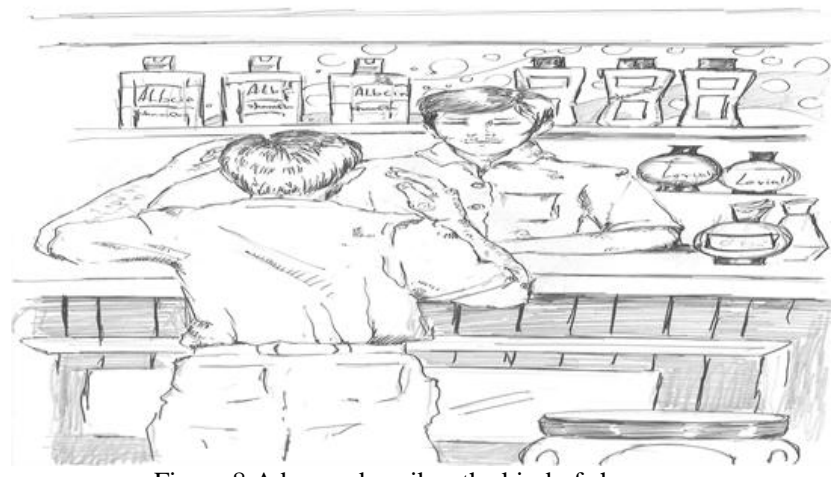

Figure 8 A buyer describes the kind of shampoo

\section{H. Charging Cell Phone}

From time to time we need to recharge our cell phones. The following situation happened to an Iraqi in (China Unicom Communication) office. When he wanted to recharge his cell phone, the woman who stands in the reception, couldn't speak English and she doesn't understand what kind of service he needs.

Speaker: Please, recharge my phone

Chinese employee: "catches the mobile phone"

Speaker: No, no, it is OK!

Chinese employee: "smiling..."

At first, a Chinese employee caught a speaker's mobile believing that it is damage. Chinese smiling is a facial expression. It is a polite message to the speaker, shows that he has a confusion to understand a speaker's need. An Iraqi speaker realized the Chinese smiling code. He acted as one needs to call and then holding money in his right hand and the cell phone in the left one, then trying to pass the money across the mobile. This acting movement tells that the speaker's need is to recharge a mobile for a selected amount of money. Fig 9 is a description of a speaker who needs to recharge phone. 


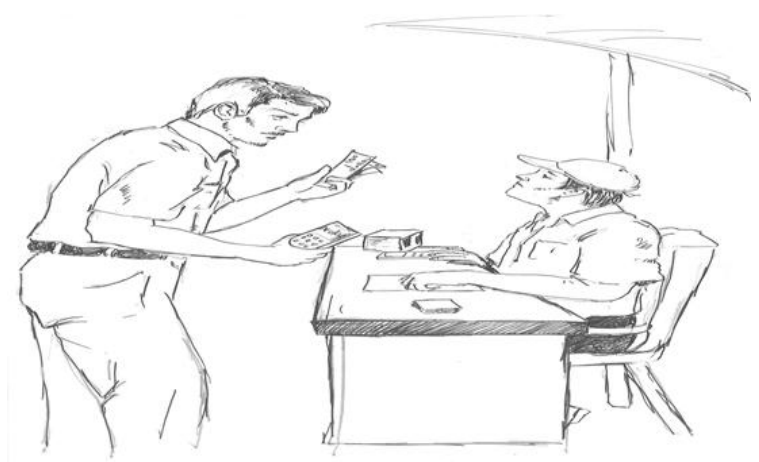

Figure 9 A customer shows the amount money of mobile recharging

\section{Puncture Maintenance}

In China, most people are using bicycles and motorcycles to avoid congestion and to ensure fast arrival. Like most students, an Iraqi uses the motorcycles to mobility from dorm to the university and vice versa. One day when he wanted to go back to his dorm after finishing his class, he noticed that the bike's tire was flat of air. To repair it, he should take it to the maintenance shop.

Driver: do you see? It is puncture!

Chinese worker: "pointing to a new tire"

Driver: puncture, puncture, man!

Chinese worker: "staring on the tire...he is thinking!!"

Chinese speaker misunderstand the message, so he thought that the speaker wanted to replace a new one of tire. Chinese still staring on the tire without speaking putting his fingers in touch with his head as if he is thinking. An Iraqi speaker tried to explain to the man what had happened but there was no benefit because a Chinese service man could not understand what a driver want to say. After that, A driver tried to act the case of puncture non-verbally. He found a small nail on the ground near to him. He hold it and put this nail into tire and making a small hole in the tire with sound (fissssss) to indicate that this nail made a hole in the tire and the air was coming out. At that moment, the man got the idea and began to repair the tire. Fig 10 shows a speaker performs movements showing the motorcycles puncture.

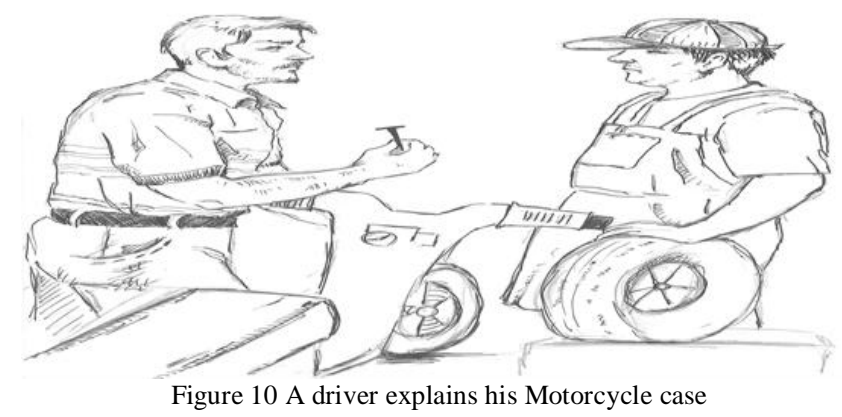

\section{CONCLUSION}

This study was an attempt to describe some non-verbal situations that happened with the researchers during their study in China. The study concluded that both of interlocutors can communicate non-verbally in spite of their different languages. The study concluded that whether the two differentiated cultures and languages of both China and Iraq, Chinese and Iraqi people share the same background knowledge about non-verbal communication. Therefore, facial expression, gestures, proxemics, ...etc. did not register any misunderstanding from both of interlocutors. There was no ambiguity in comprehending Iraqi's movements, it could be easy to recognize by another interlocutor. Therefore, waving hand to the right and to the left; collecting hands together; holding something; joining something; moving hand from top to the bottom etc. are signs that non-verbal communication can serve as verbal language in many of the situations. It also concluded that whether verbal language is the way of real communications in all aspects of the life, non-verbal communication can substitute verbal language if there were barriers prevent the interlocutors from using it. 


\section{ACKNOWLEDGMENTS}

The authors would like to thank Mr. Hayder Tuama Jasam for his invaluable suggestions. They also would like to thank Miss. Zahraa Mahood for her contribution in drawing the figures that fit the chosen research situations.

\section{REFERENCES}

[1] Barry, B. E., Bodenhamer, J., \& O'Brien Jr, J. J. (2011). Student nonverbal communication in the classroom. In American Society for Engineering Education. American Society for Engineering Education.

[2] Ben-Nun, L. (2014). Non-verbal communication. Israel: Ben-Gurion University of Negev.

[3] Caris-Verhallen, W. M., Kerkstra, A., \& Bensing, J. M. (1999). Non-verbal behavior in nurse-elderly patient communication. Journal of Advanced Nursing 29.4, 808-818.

[4] Dinica, Razvan C. (2014). Non-verbal communication-indispensable complement of oral and written communication. Procedia-Social and Behavioral Sciences 137, 105-111.

[5] Guerrero, L. K., \& Floyed, K. (2006). Nonverbal communication in close relationships. London: Rutledge.

[6] Halliday, M.A. (1993). Towards a language-based learning. Linguistics and Education 5.2, 93-116.

[7] Hess, U. (2016). Nonverbal communication. Howard S. Friedman Encyclopedia of Mental Health (2 ${ }^{\text {nd }}$ edn.,3), Waltham, MA: Academic Press, 208-218.

[8] Poole, Stuart C. (2000). An introduction to linguistics. UK: Foreign Language Teaching and Research Press.

[9] "Principles". (2014). Principles and functions of nonverbal communication, section (4-1). Washington: The Saylor Foundation.

[10] Runqing, Liu. (2002). Theories and schools of linguistics. Beijing: Beijing Foreign Studies University.

[11] Topan, F. (2011). Nonverbal communication. A cultural guide. Revista Transilvană. de Stiinţe ale Comunicării 3.14,132 -141.

[12] Wharton. M. (2009). Pragmatics and non-verbal Communication. Cambridge: Cambridge University Press.

[13] Yang, P. (2017). Intercultural nonverbal communication competence as intercultural responsiveness in the second language learning classroom. In multicultural Instructional Design: Concepts, Methodologies, Tools, and Applications, 127-147. IGI Global.

Khalid Wahaab Jabber was born in Iraq. He has got his Master degree in Applied Linguistics from the School of Foreign Languages /Huazhong University of Science and Technology, China. Now he is an instructor of English language at department of English /University of Misan. His main interests include; pragmatics, discourse analysis, and cognitive linguistics.

Aymen Adil Mahmood was born in Iraq. He has got his Master degree in Applied Linguistics from the School of Foreign Languages /Huazhong University of Science and Technology, China. Now he teaches English language at Diyala Directorate of Education. His research interests are semantics and pragmatics. 